\title{
Article \\ Hemispheric Asymmetry in Visual Processing: An ERP Study on Spatial Frequency Gratings
}

\author{
Alice Mado Proverbio ${ }^{1, *(1)}$ and Alberto Zani ${ }^{2}$ (]) \\ 1 Department of Psychology, University of Milano-Bicocca, 20126 Milan, Italy \\ 2 School of Psychology, Vita-Salute San Raffaele University, 20121 Milan, Italy; zani.alberto@hsr.it \\ * Correspondence: mado.proverbio@unimib.it
}

check for

updates

Citation: Proverbio, A.M.; Zani, A Hemispheric Asymmetry in Visual Processing: An ERP Study on Spatial Frequency Gratings. Symmetry 2021, 13, 180. https://doi.org/10.3390/ sym13020180

Academic Editor: Vilfredo De Pascalis Received: 31 December 2020

Accepted: 20 January 2021

Published: 23 January 2021

Publisher's Note: MDPI stays neutral with regard to jurisdictional claims in published maps and institutional affiliations.

Copyright: (c) 2021 by the authors. Licensee MDPI, Basel, Switzerland. This article is an open access article distributed under the terms and conditions of the Creative Commons Attribution (CC BY) license (https:// creativecommons.org/licenses/by/ $4.0 /)$.

\begin{abstract}
A hemispheric asymmetry for the processing of global versus local visual information is known. In this study, we investigated the existence of a hemispheric asymmetry for the visual processing of low versus high spatial frequency gratings. The event-related potentials were recorded in a group of healthy right-handed volunteers from 30 scalp sites. Six types of stimuli $(1.5,3$ and $6 \mathrm{c} / \mathrm{deg}$ gratings) were randomly flashed 180 times in the left and right upper hemifields. The stimulus duration was $80 \mathrm{~ms}$, and the interstimulus interval (ISI) ranged between 850 and $1000 \mathrm{~ms}$. Participants paid attention and responded to targets based on their spatial frequency and location. The C1 and P1 visual responses, as well as a later selection negativity and a P300 component of event-related potentials (ERPs), were quantified and subjected to repeated-measure analyses of variance (ANOVAs). Overall, the performance was faster for the right visual field (RVF), thus suggesting a left hemispheric advantage for the attentional selection of local elements. Similarly, the analysis of the mean area amplitude of the $C 1(60-110 \mathrm{~ms})$ sensory response showed a stronger attentional effect $(\mathrm{F}+\mathrm{L}+\mathrm{vs}$. $\mathrm{F}-\mathrm{L}+)$ at the left occipital areas, thus suggesting the sensory nature of this hemispheric asymmetry.
\end{abstract}

Keywords: ERPs; selective attention; global and local; cerebral hemispheres; VEPs; spatial frequency; attentional tuning; left hemisphere

\section{Introduction}

The issue of a hemispheric asymmetry in the perceptual processing of visual information has been largely debated [1-10]. The main lines of research and theoretical discussions have led to the conclusion that there might be a hemispheric asymmetry (1) in the way the left and right hemispheres process information in an analytic vs. holistic manner, or (2) in the way they select object features as opposed to paying sustained attention in space, and (3) it was argued that, probably, the two hemispheres possess functional and neuroanatomical differences that render them more able to process information, based on a low vs. high spectrum of spatial frequency (magno- vs. parvo-cellular content). These three approaches, and the experimental evidence supporting them, are briefly discussed below.

\subsection{The Role of the Right vs. Left Hemisphere in Global and Local Processing}

Robertson et al. [11] theorized that a hemispheric asymmetry existed for the processing of the global versus local content of visual information, with a left hemispheric advantage for the local analysis and a right hemispheric advantage for the global analysis. In an interesting neuropsychological study, Robertson et al. [12] found that a left temporoparietal lesion compromised the patients' ability to reproduce the local elements of both geometrical and linguistic hierarchical stimuli (so-called Navon configurations [13]), while a right-sided lesion compromised the patients' ability to reproduce their global form.

These findings are consistent with the existence of a right-sided neural circuit devoted to the precession of global (versus local) information [14-16]. For example, Yamaguchi 
et al. [6] found that the local versus global elements of compound stimuli in an attention task were associated with enlarged N2 deflections (250-350 ms) over the left versus the right hemispheric areas. Again, Proverbio et al. [17] found a greater amplitude in the N2 responses to subtle illusory contours over the left occipital areas. These findings hint at the view of a left hemispheric dominant role in the ability to process and select visual stimulus details and local information [16,18].

\subsection{Object-Based vs. Space-Based Hemispheric Asymmetry}

On another side, other evidence has been offered for the existence of a hemispheric asymmetry for space-based (as opposed to object-based) selective attention, in favor of the right vs. left hemisphere [9,19-21]. In an electrophysiological investigation by Proverbio et al. (2004), participants were shown pictures of animals and objects, either in their prototypical color or in an unassociated color (e.g., pink vs. blue piglets). The target stimuli associated with the prototypical combination of color and shape triggered enhanced N2 potentials (or selection negativity (SN)) over the occipitotemporal areas, compared with the unassociated combination. This color-specific effect was observed only over the left hemisphere, as it was also observable from the topographic distribution of the N2 difference voltage (prototypical minus non-prototypical color). These findings seem to suggest the predominant role of the left occipitotemporal cortex in the processing of object features. Similarly, Orlandi and Proverbio [22] showed a left-hemispheric selectivity in the ability to discriminate object shapes, as indexed by the amplitude of the $\mathrm{SN}$ response. Subjects were shown tridimensional pictures of schematic bodies, familiar objects such as chairs, and Shepherd cubes, which were displayed in standard or rotated views. The results showed a left hemispheric advantage for the attentional selection, resulting in an enhanced $\mathrm{SN}$ to the targets, over the left occipitotemporal sites. The standardized weighted Low-Resolution Electromagnetic Tomography (swLORETA) performed on EEG signals in the SN time range showed left lateralized neural sources, including the left superior-middle temporal (BA 22) and the left inferior frontal-precentral gyri. On the other side, many different studies support the view of right hemispheric control and dominance for the visuospatial orienting of attention, such as [23-25].

\subsection{The Spatial Frequency Hypothesis}

According to some researchers $[10,18,26,27]$, asymmetry in perceptual strategy would be grounded on a lower level (sensory) hemispheric asymmetry for processing the spatial frequency content of visual information. There would be a right hemispheric advantage for processing the low spatial frequency range, and a greater left hemispheric ability for processing finer details, such as the high spatial frequency spectrum. Dos Santos et al. [28] investigated the hemispheric specialization for spatial frequency processing by measuring the contrast sensitivity curves of sinusoidal gratings in 30 patients with left or right brain damage. The results showed that patients with left brain damage were selectively impaired in high-frequency processing, while patients with right brain damage were more impaired in low-frequency processing. These findings can be interpreted in terms of a hemispheric asymmetry for spatial frequency discrimination.

Furthermore, the electrophysiological investigation by Martínez et al. [27] reported a larger SN component in response to target than non-target checkboard patterns. The attentional selection of high spatial frequencies elicited larger $\mathrm{SN}$ responses over the left hemisphere, while the attentional selection of low spatial frequencies elicited larger SN responses over the right hemisphere, thus indicating a hemispheric asymmetry for spatial frequency processing. Similarly, Proverbio et al. [26] recorded visual evoked potentials to spatial frequency gratings and found that the N80 and P1 responses were differentially modulated by spatial frequency content. The N80 potential exhibited a negative focus over mesial occipital sites, whereas the P1 component exhibited a positive focus, which was maximal over the lateral occipital sites. Moreover, the positive peak was larger over the right hemisphere, while the negative peak (N80) shifted from the right to the 
left hemisphere as the spatial frequency increased. Therefore, early visual potentials elicited by low vs. high spatial frequencies showed a differential polarity and topographic distribution, which might reveal the activity of topographically segregated and functionally distinct neural sources (possibly reflecting a prevalence of magnocellular vs. parvocellular information), as a function of the spatial frequency.

These results of a hemispheric asymmetry for sensory processing are also consistent with those reported by Zani and Proverbio [29] in their event-related potential (ERP) study on selective attention to check size. In that study, relevant checks elicited larger ERP components at both the occipital (N165 and P3b) and frontal (long latency positivity (LP)) scalp sites over the left-but not the right-hemisphere, as compared to the irrelevant ones. Moreover, right- and left-sided hemispheric asymmetries were found, being consistent with a P90 right-sided specialization for low spatial frequencies and an N115 left-sided specialization for high spatial frequencies, respectively.

Notwithstanding the bulk of evidence of left-sided attentional ERP components (such as selection negativity or N2 responses), the evidence of lateralized attention effects indexed by sensory potentials is quite scarce. In the present study, visual ERPs were recorded in healthy participants during the perception and attentional selection of non-square or wave spatial frequency gratings. The $\mathrm{C} 1$ and $\mathrm{P} 1$ sensory responses were measured to obtain data about a possible hemispheric asymmetry in attentional selection. This was made possible by the comparison of the attentional effects measured on left and right hemispheric sites of recording. The longer-latency selection negativity and P300 responses were also measured, and an increase in their amplitude as result of attentional selection was expected, based on the previous investigations of Harter's research group [30-32].

There is much evidence in the psychophysiological literature that the morphology of the visual sensory components (C1 and P1) is strongly modulated by a series of stimulus physical characteristics, such as the orientation, the spatial frequency and the visual field of presentation of the gratings and checkerboards [33-36]. On the basis of the previous literature, we expected that $\mathrm{C} 1$ would be larger at the ipsilateral sites, whereas P1 would be larger at the contralateral sites. Moreover, $\mathrm{C} 1$ would have a mesial occipital distribution and P1 a lateral occipital distribution [26]. Finally, an early object-based attention modulation of both the $\mathrm{C} 1$ and $\mathrm{P} 1$ responses, such as in [37], was expected.

\section{Materials and Methods}

\subsection{Participants}

Eight healthy students (4 females and 4 males) with normal or lens-corrected vision took part in the study. Their mean age (ranging between 24 and 33 years) was 28.5 years, and their socioeconomic and cultural levels were similar. All participants were psychically and neurologically healthy. Half of the women were in the premenstrual phase, and the other half were in the postmenstrual phase of their cycles. Before the EEG recording, they were asked to fill in the informed consent to the research and the documentation regarding the minimum risk. They were then administered the Edinburgh Inventory to assess their right-handedness. The experiments were conducted with the understanding and written consent of each participant, according to the Declaration of Helsinki (BMJ 1991; 302: 1194) and the approval of the local ethical committee (University of Trieste). One subject was discarded in subsequent statistical analyses for excessive ocular artifacts.

\subsection{Stimuli}

The stimuli were three spatial frequency gratings, whose contrast was degraded to obtain a quasi-sinusoidal luminance variation. Their spatial frequencies were 1.5, 3 and 6 cycles per degree (c/deg) at the viewing distance of $114 \mathrm{~cm}$, respectively. The gratings were briefly flashed in the upper left visual hemifield (ULH) or right visual hemifield (URH) with respect to the center of the screen, where a small cross acted as fixation point (see Figure 1a). 
(a)
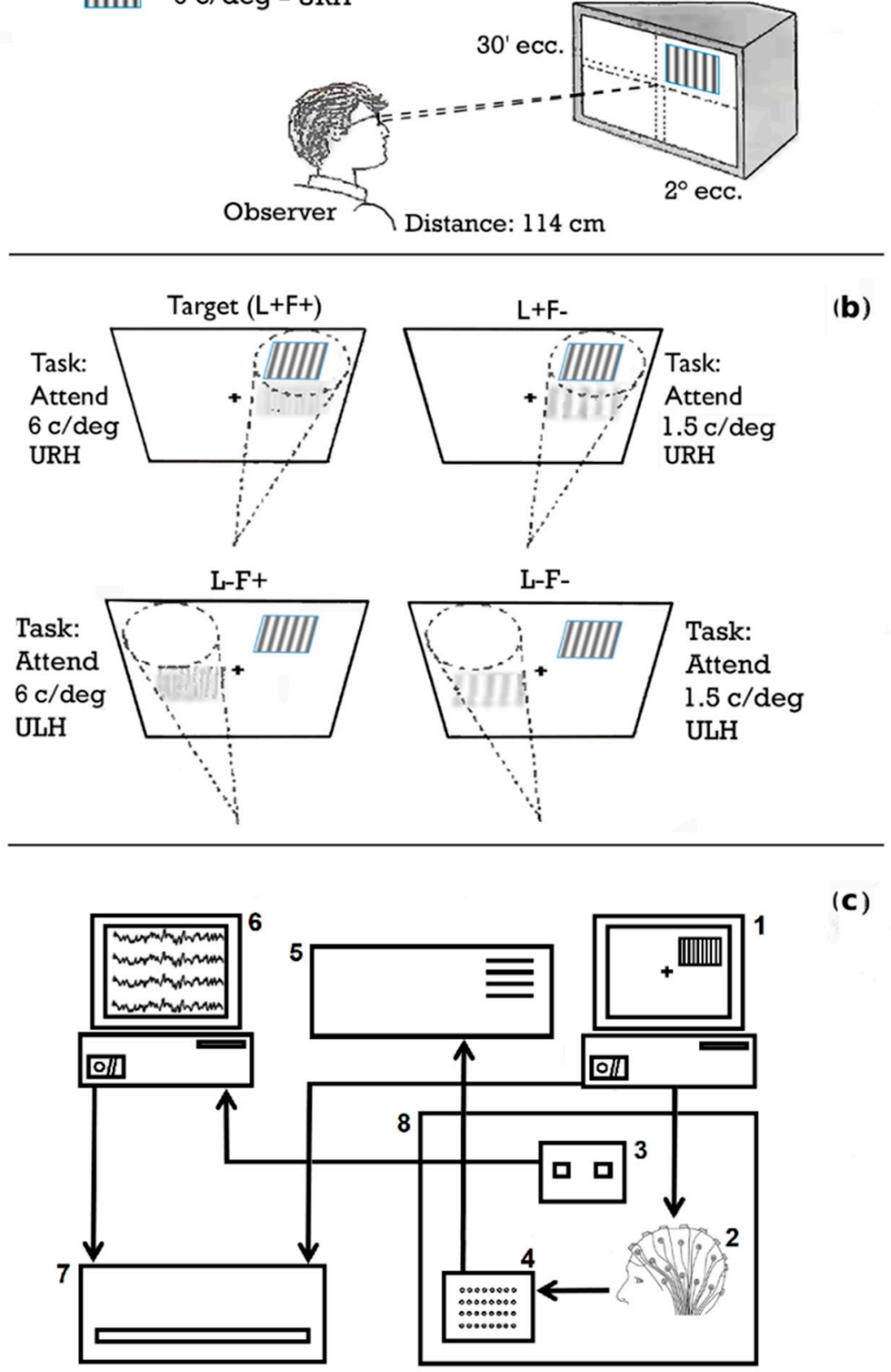

(c)

Figure 1. (a) Sketch of the experimental procedure, showing the viewing distance and the stimulus eccentricity. (b) Example of task manipulation for a $6 \mathrm{c} / \mathrm{deg}$ spatial frequency grating presented in the upper right hemifield (URH). The dashed, tilted cones symbolize the focus of the covert orienting of attention toward one spatial location. Therefore, in the upper left, the grating is relevant both in location and in frequency, because its spatial frequency is a target (as indicated by the gray, shadowy grating depicted outside the circular base of the focus of attention) and spatial attention is directed toward the URH, as indicated by the tilted cone. Conversely, in the upper right, the same grating is irrelevant in frequency, but relevant in location (i.e., $\mathrm{L}+\mathrm{F}-$ ). The other two cases are relevant in spatial frequency but not in location (lower left) and irrelevant in both features (lower right). (c) EEG recording set-up: (1) 17 in IBM monitor with STIM software, (2) head of the subject wearing an Electro-Cap, (3) response keys, (4) an EEG connection plate, (5) 32 channel amplifiers, (6) 22 in IBM monitor with SCAN and RESPWIN software, (7) a color printer and (8) a soundproof cabin.

The background was gray and isoluminant with respect to the gratings to avoid perceptual aftereffects or consecutive image phenomena. Within each quadrant, the stimulation started at $0^{\circ} 30^{\prime}$ at a visual angle above the fixation point and extended up to $4^{\circ} 30^{\prime}$ 
above it, while laterally the stimulus started from $2^{\circ}$ and went up to $6^{\circ} 03^{\prime}$. The stimulus duration was $80 \mathrm{~ms}$. The interstimulus interval (ISI) ranged randomly between 850 and $1000 \mathrm{~ms}$. Since the participants had to keep their gaze on the fixation point, the decentralization of the stimuli allowed the stimulation of the extrafoveal retinal areas. The gratings presented to the left or to the right with respect to the fixation point were reversed by $180^{\circ}$ in order to obtain specular stimuli that provided an identical cortical representation, whether they were projected to the right or left of the hemiretinas.

\subsection{Procedure}

The subjects were provided with written instructions describing the experimental task. A training phase preceded the experimental session, so that participants might familiarize with the different types of stimuli and the experimental setting. This training phase ended when the subject showed an optimal ability to discriminate the various spatial sequences of the gratings.

The six types of stimuli ( 3 frequencies for 2 locations) were projected in a random order 180 times (30 repetitions for each type of stimulus). The participants were administered 30 different sequences (of 180 stimuli each), featuring a specific stimulus selection task requirement. At the beginning of each run, the subjects were given the experimental instructions of paying attention to the gratings of one specific frequency at one spatial location (e.g., during this run, pay attention and respond to the high frequency grating to the right visual field, and ignore all other types of stimuli). The participants were instructed to press a button with the index finger of one of the two hands as quickly and efficiently as possible while ignoring non-target stimuli. In half of the trials, the subjects used the right hand, and in the remaining half, the left hand was used. The order of the hands was randomized between trials and between subjects. Each sequence was followed by a short pause, while every $15 \mathrm{~min}$, a longer pause was given to the subjects. The whole experimental procedure lasted $\sim 1 \mathrm{~h}$. There were four attentional conditions: attention to the $6 /$ deg spatial frequency gratings on the right, to the $6 /$ deg spatial frequency gratings on the left, to the $1.5 \mathrm{c} / \mathrm{deg}$ spatial frequency gratings on the right and to the $1.5 \mathrm{c} / \mathrm{deg}$ spatial frequency gratings on the left. The $3 \mathrm{c} / \mathrm{deg}$ spatial frequency gratings were included as distractor stimuli, since they were never a target. The stimuli might therefore be targets in both spatial frequency and location $(\mathrm{L}+\mathrm{F}+)$, targets only in location $(\mathrm{L}+\mathrm{F}-)$, targets only in spatial frequency $(\mathrm{L}-\mathrm{F}+$ ) or non-targets for both dimensions $(\mathrm{L}-\mathrm{F}-$ ) (see Figure $1 \mathrm{~b}$ ).

\subsection{EEG Recordings}

The participants sat inside a silent cubicle with medium soundproofing and weak symmetrical lighting in front of a double-glazed window measuring $70 \times 55 \mathrm{~cm}$. Outside the cubicle was a 17 in Macintosh monitor used for the presentation of visual stimuli which was connected to an IBM PC controlling the stimulus presentation, located outside the cubicle. A 30 channel Electro-Cap was applied to each subject for recording his or her EEG waves. Two extra pairs of surface electrodes were applied to record vertical and horizontal ocular movements via an electrooculogram (EOG). Averaged ears acted as reference electrodes. All the electrodes were connected to a panel interfaced with a 32 channel SynAmps amplifier (see Figure 1c). The amplification unit was in turn connected to another IBM PC, in which NeuroScan 3.0 software controlled the continuous recording of the EEG traces and stimulus-response synchronization. The subjects responded through a StimPad push-button panel interfaced with NeuroScan 3.0 software, so that the response signals, recorded on the row traces, might later be analyzed through Respwin software in order to obtain the data relating to the behavioral performance of the subjects.

The EEG data were continuously recorded from 30 scalp sites, according to the 10-20 International System, at a sampling rate of $500 \mathrm{~Hz}$. Two pairs of bipolar electrodes were applied to the subject for the detection of horizontal and vertical eye movements. Two electrodes placed on the earlobes were used as reference electrodes, while the ground electrode was included in the recording cap in the center frontal position. The EEG and 
electrooculogram (EOG) were filtered with a half-amplitude band pass of $0.016-50 \mathrm{~Hz}$. The electrode impedance was maintained below $5 \mathrm{k} \Omega$. Computerized artifact rejection was performed prior to averaging in order to discard epochs in which ocular movements, blinks or other artifacts occurred. The artifact rejection criterion was a peak-to-peak amplitude exceeding $50 \mu \mathrm{V}$ and resulted in a rejection rate of $\sim 15 \%$. Event-related potentials (ERPs) going from $100 \mathrm{~ms}$ before stimulus onset through $1000 \mathrm{~ms}$ after stimulus onset were averaged offline. The ERP components were measured when in time and where on the scalp they reached their maximum amplitudes.

\subsection{Statistical Analysis}

For each subject, the mean area amplitude values of the C1 (60-110 ms), P1 (110-160 ms), selection negativity (N2, 165-330 ms) and P300 (330-600 ms) ERP responses were quantified and subjected to repeated-measures analyses of variance (ANOVAs). The ERP responses to the target gratings $(1.5 \mathrm{c} / \mathrm{deg}$ left, $1.5 \mathrm{c} / \mathrm{deg}$ right, $6 \mathrm{c} / \mathrm{deg}$ left, $6 \mathrm{c} / \mathrm{deg}$ right) were compared to the responses to the same gratings in the other attention conditions (when irrelevant or when sharing one feature (i.e., either frequency or location) with the target). The factors were the attentional condition, hemisphere (for the $\mathrm{C} 1$ and $\mathrm{P} 1$ components) and the electrode. The attentional condition had 4 levels of variance: target $(\mathrm{L}+\mathrm{F}+)$, locationspecific $(\mathrm{L}-\mathrm{F}+)$, frequency-specific $(\mathrm{L}+\mathrm{F}-)$ and irrelevant $(\mathrm{L}-\mathrm{F}-)$. The hemisphere had 2 levels of variance (left and right). The electrode had 3 levels of variance: occipital (O1, $\mathrm{O} 2)$, lateral occipital (OL-OR) and occipitotemporal (T5-T6) for the sensory components $\mathrm{C} 1$ and P1 and 9 levels for later components' selection negativity and P300 (O1, O2, OL, OR, T5, T6, Oz, Cz and Pz).

The response times (RTs) and percentage of correct responses (hits) were recorded and quantified. RTs that exceeded the mean value \pm 2 standard deviations were discarded, which resulted in a rejection rate of approximately 5\%. Both the RTs and accuracy percentages were subjected to separate multifactorial repeated-measures ANOVAs with 3 within-subject factors, whose factors of variability were the visual field of presentation (left or right), grating spatial frequency ( 1.5 or $6 \mathrm{c} / \mathrm{deg}$ ) and response hand (left or right). The significance acceptance level was $p<0.05$.

\section{Results}

\subsection{Behavioral Data}

The analysis of variance performed on the response times of the subjects did not result in any statistical significance, except for a very close to significant visual field factor for reaction times analyses $(\mathrm{F}(1,6)=5.6, p=0.055)$. The response times were faster when the stimuli were presented in the upper right visual hemifield (URH, left hemisphere), compared with the upper left visual hemifield (ULH, right hemisphere). False alarm responses incorrectly directed to non-targets (e.g., $3 \mathrm{c} / \mathrm{deg}$ gratings) were less than $2 \%$ of the total amount of emitted responses. The omissions (lack of response to 1.5 and $6 \mathrm{c} / \mathrm{deg}$ target gratings) were slightly superior to $3 \%$ of the emitted responses. Accuracy analyses did not yield any statistical significance.

\subsection{Electrophysiological Data \\ 3.2.1. C1 Component}

The $\mathrm{C} 1$ response was much larger in the ipsilateral than contralateral field (see Figure 2), as shown by the hemisphere $\times$ visual field factors interaction $(F(1,6)=14.3$, $p<0.009$ ). Indeed, the $\mathrm{C} 1$ responses were much larger over the left hemisphere for the left visual field (LVF) gratings, and vice versa over the right hemisphere for the RVF ones. 

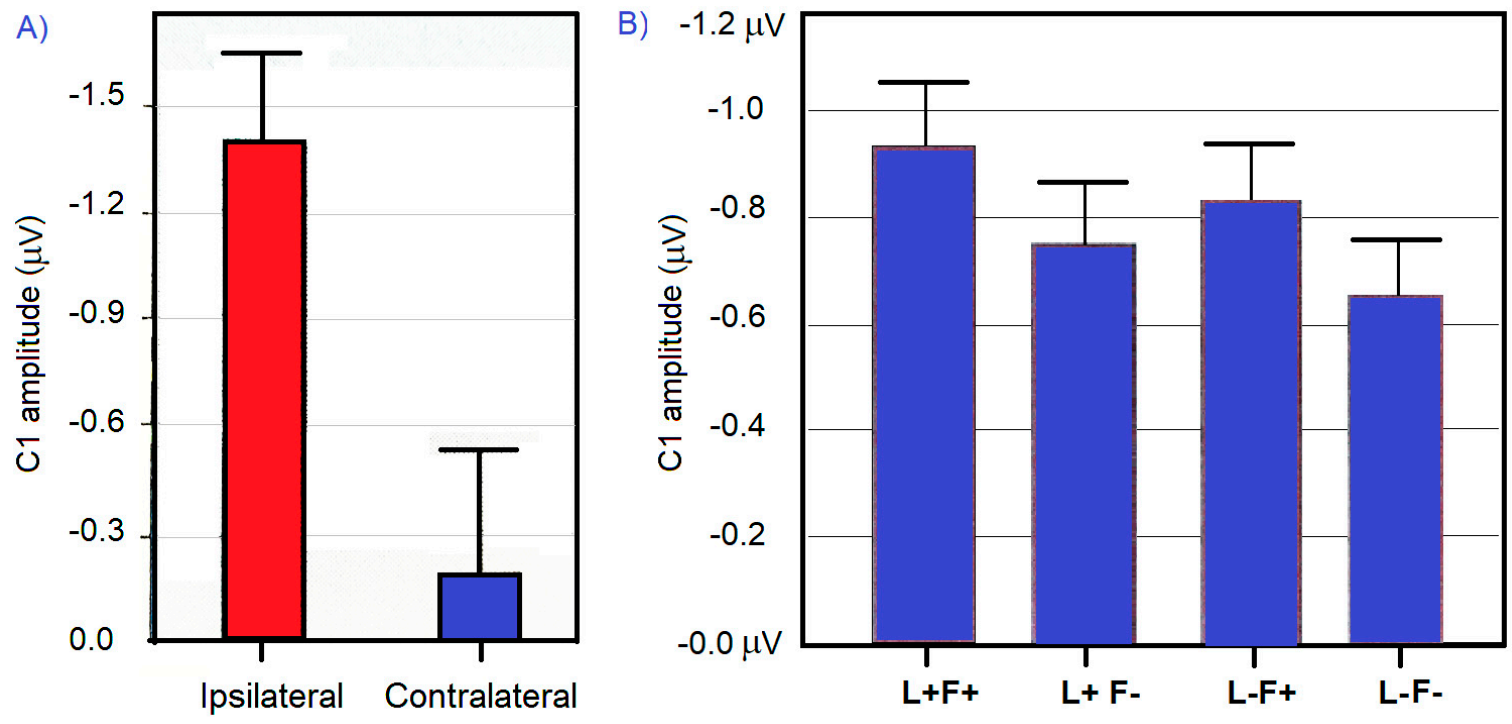

Figure 2. (A) Mean amplitude values of the $C 1$ responses recorded at ipsilateral vs. contralateral stimuli, regardless of the attentional condition. (B) Mean amplitude values of the $\mathrm{C} 1$ responses recorded in different attentional conditions, regardless of the spatial frequency of stimulation.

The significance of the electrode $\mathrm{x}$ spatial frequency factors $(\mathrm{F}(2,12)=16.3, p<0.001)$ showed a larger $\mathrm{C} 1$ response over the striate $(\mathrm{O} 1, \mathrm{O} 2)$ than extra-striate (OL and $\mathrm{OR})$ and occipitotemporal sites (T5, T6), especially for the higher spatial frequency.

The $\mathrm{C} 1$ response was strongly modulated by attentional factors in interaction with the cerebral hemisphere $(\mathrm{F}(4,24)=3.8, p<0.01)$. Post hoc comparisons showed that for both the $6 \mathrm{c} /$ deg gratings $(p<0.001)$ and the $1.5 \mathrm{c} /$ deg gratings, the frequency-based attentional effect $(\mathrm{L}+\mathrm{F}+\mathrm{vs}$. $\mathrm{L}+\mathrm{F}-)$ was much larger over the left hemisphere (irrespective of the visual field of stimulation), as can be appreciated in Figure 3. In addition, the main effect of the attentional task $(\mathrm{F}(4,24)=3.1, p<0.03)$ was significant, with a larger $\mathrm{C} 1$ to target $(\mathrm{L}+\mathrm{F}+)$ than the location-specific $(\mathrm{L}-\mathrm{F}+)$ or frequency-specific $(\mathrm{L}+\mathrm{F}-)$ non-targets, which in turn were more negative than the $\mathrm{C} 1$ to irrelevant stimuli $(\mathrm{L}-\mathrm{F}-)$, as demonstrated by post hoc comparisons among the means $(p<0.002)$, as is visible in Figure 4.

\subsubsection{P1 Component}

The significant electrode factor showed that $\mathrm{P} 1$ was more focused over the occipital $(\mathrm{O} 1, \mathrm{O} 2, \mathrm{OL}$ and $\mathrm{OR})$ than the inferior temporal scalp areas $(\mathrm{F}(2,12)=4.68, p<0.03)$, as is also visible in the topographical maps of Figure 5.

The ANOVA yielded the significant effect of the attention condition $(\mathrm{F}(4,24)=4.08$, $p<0.02)$, with larger P1 responses to the target than the location-specific stimuli $(p<0.025$, $\mathrm{L}-\mathrm{F}+$ ) and, in turn, to location- and frequency-specific rather than irrelevant gratings (as shown by post hoc comparisons, $p<0.001$ ). The attentional effect was smaller for the stimuli presented in the LVF (right hemisphere), as shown by the significant triple interaction of attention $\mathrm{x}$ electrode $\mathrm{x}$ hemisphere $(\mathrm{F}(8,48)=2.2, p<0.04)$. Furthermore, the frequency-specific effects $(\mathrm{L}+\mathrm{F}+\mathrm{vs}$. $\mathrm{L}+\mathrm{F}-)$ were larger $(p<0.01)$ at the striate and extra-striate than inferior temporal scalp areas.

\subsubsection{Selection Negativity (SN)}

The ANOVA performed on the SN mean area amplitude values showed a significant effect from the attention condition $(\mathrm{F}(4,24)=8.3, p<0.001)$. Post hoc comparisons showed large statistical differences between the $\mathrm{SN}$ to the targets and all other stimulus types (see Figure 6a). The significance of the electrode factor $(\mathrm{F}(2,12)=5.02 ; p<0.02)$ and relative post hoc comparisons showed that the $\mathrm{SN}$ was of a maximal amplitude over the occipital scalp sites. 


\subsubsection{P300 Component}

The ANOVA performed on the P300 amplitude values gave rise to the significance of the attention factor $(\mathrm{F}(32,192)=9.5, p<0.001)$. Post hoc comparisons showed that P300 was largely greater to the targets than all other stimulus types (see Figure $6 \mathrm{~b}$ ). The further interaction of attention $\times$ electrode $(\mathrm{F}(4,240)=24.8, p<0.001)$ showed the P300 was of a maximal amplitude at the centro-parietal sites, as can be clearly appreciated by looking at the amplitude data in Figure 7.
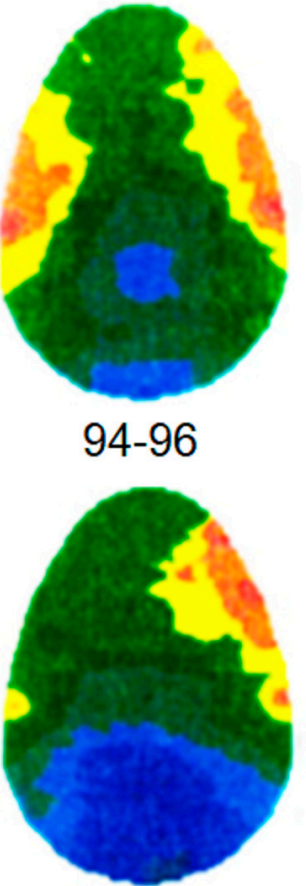

102-104

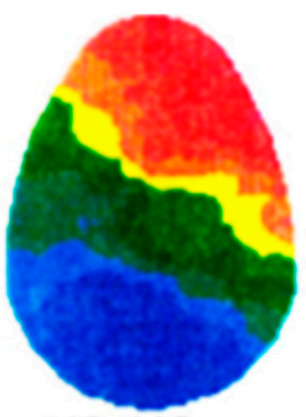

$110-112$
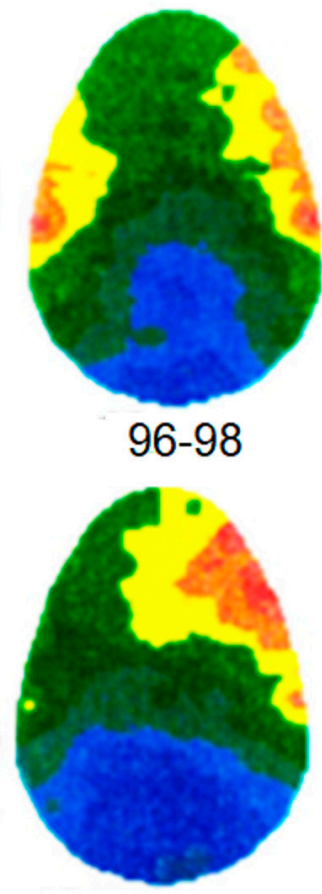

104-106

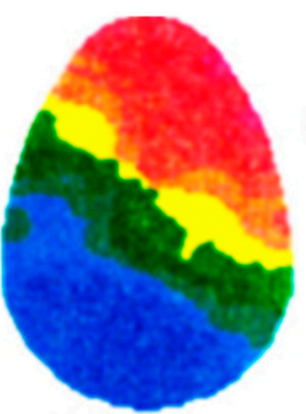

$112-114$

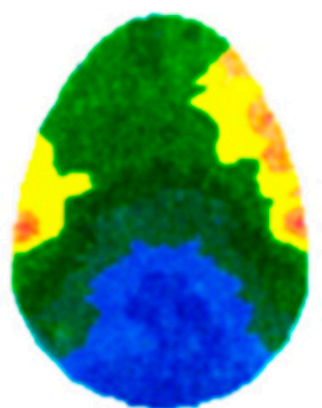

98-100

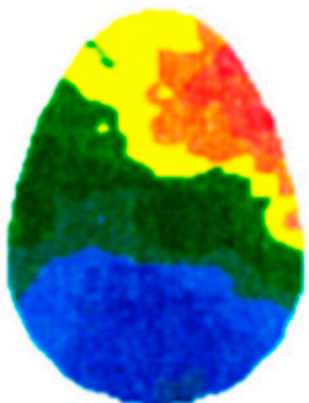

106-108

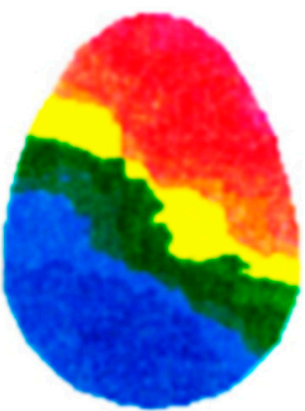

114-116

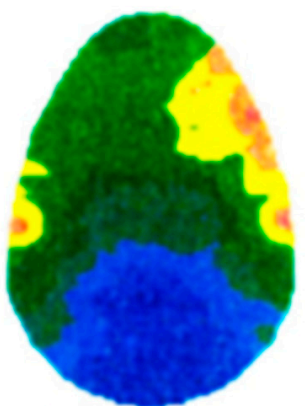

100-102

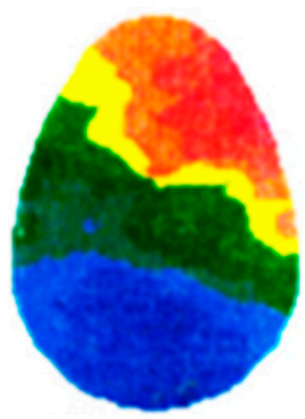

108-110

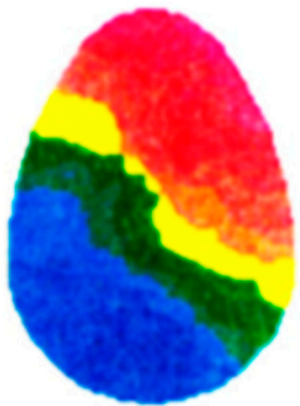

116-118

Figure 3. Effect of spatial frequency-specific attentional selection ( $\mathrm{L}+\mathrm{F}+$ minus $\mathrm{L}+\mathrm{F}-)$, regardless of the visual field of presentation, as well as the temporal series of topographical distribution of the surface voltage (top view) recorded between 94 and $118 \mathrm{~ms}$ of post-stimulus latency (every $2 \mathrm{~ms}$ ) in the C1 latency range. The data indicate an early enhanced negativity (larger $\mathrm{C} 1$ response) to the target frequencies focused over the mesial occipital scalp areas, which progressively spread over the scalp in time. A hemispheric asymmetry in the topographical distribution of attentional selection is also visible. The asymmetry would indicate a greater ability of the left visual cortex in the discrimination of fine differences in spatial frequency. 


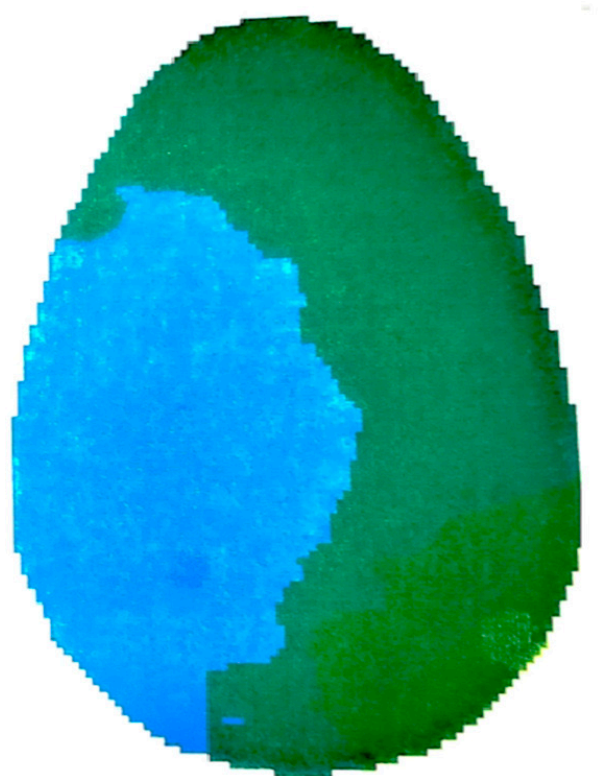

Non-target

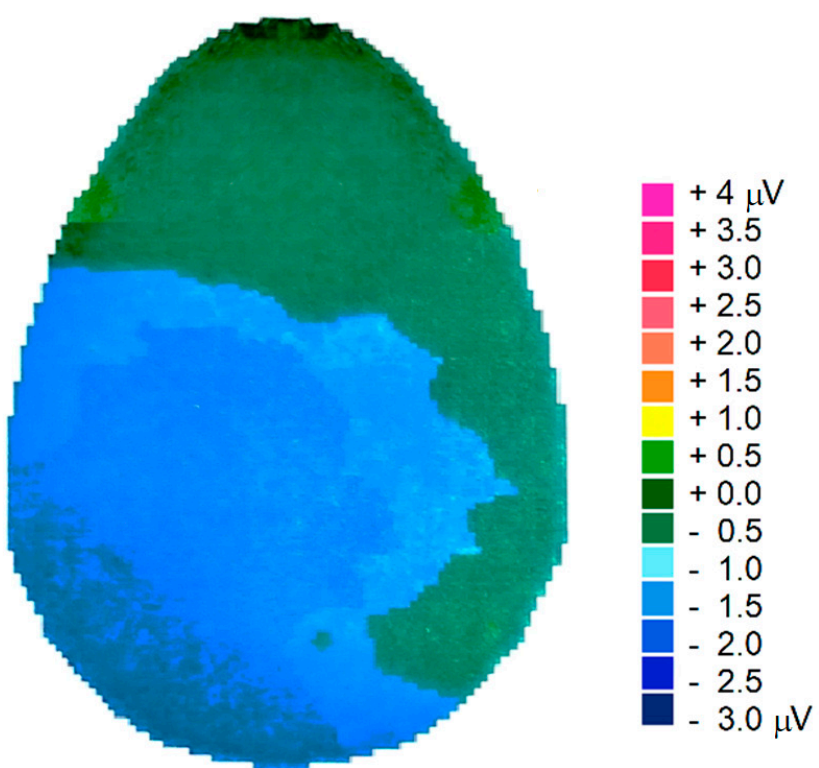

Target

Figure 4. Topographical maps (top view) of the scalp voltage of the $\mathrm{C} 1$ component, recorded in response to $1.5 \mathrm{c} / \mathrm{deg}$ gratings in the left visual field in the presence of both the target and the non-target. As can be observed, the response was ipsilateral to the stimulated field and was modulated by attention, being more negative to the target gratings than the non-target gratings.

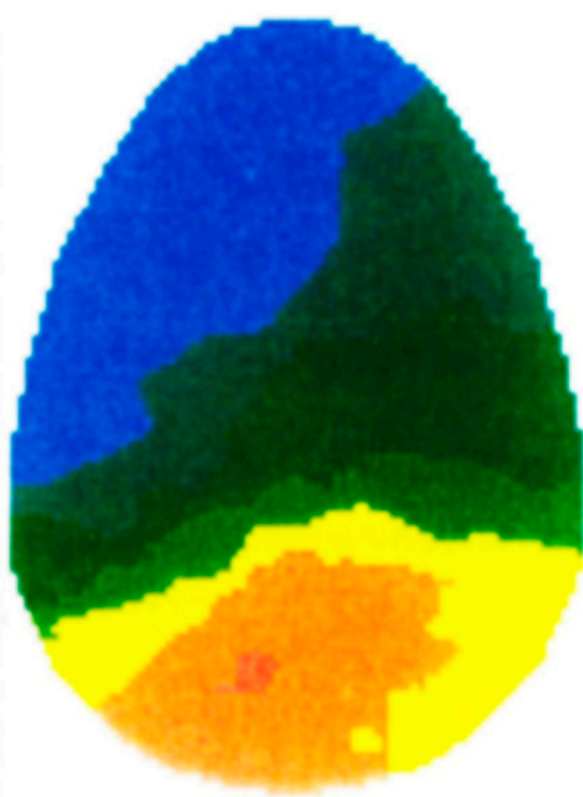

Target 120-125 ms

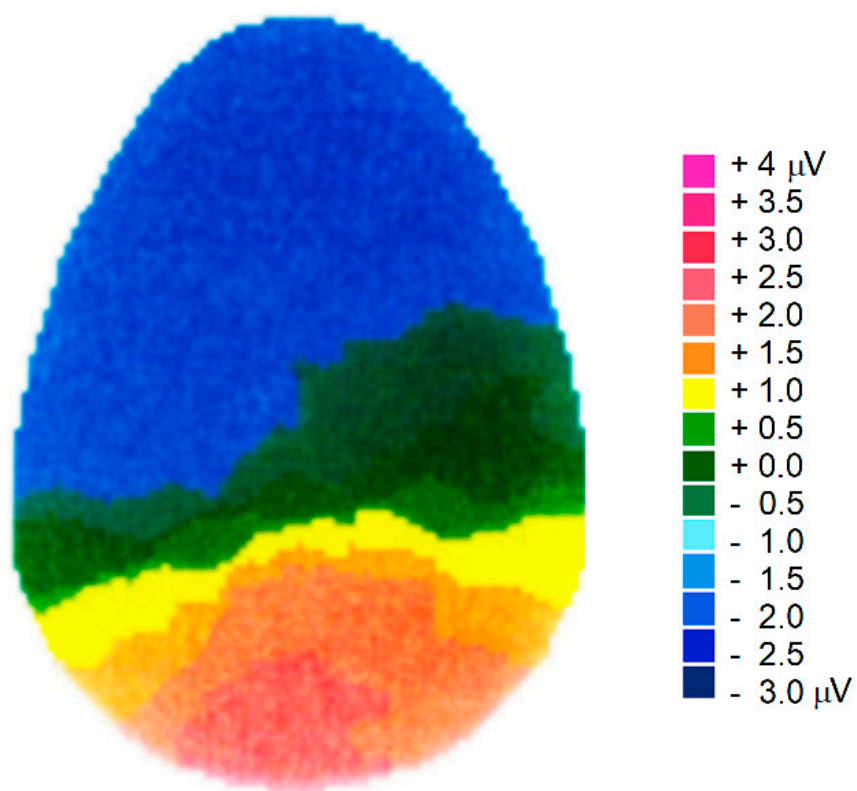

Target $130-135 \mathrm{~ms}$

Figure 5. Topographical maps (top view) of the scalp voltage of the P1 component, recorded in response to the $1.5 \mathrm{c} / \mathrm{deg}$ gratings presented in the RVF. As can be seen, the elicited positive potential was first contralateral to the stimulated field (left hemisphere) and then, as time progressed, it propagated to the ipsilateral side. 

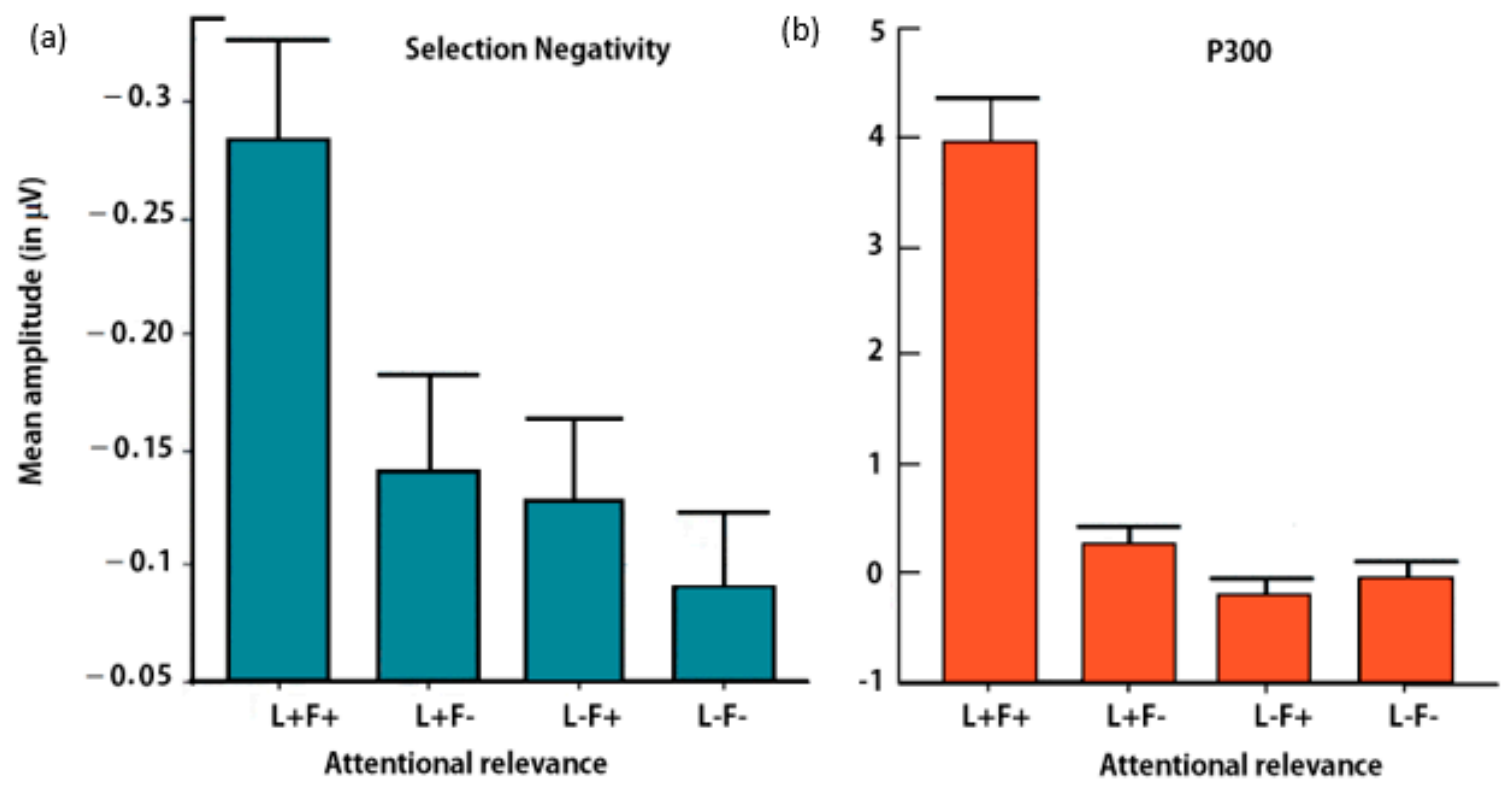

Figure 6. (a) Mean amplitude values of the selection negativity (165-330 ms), recorded in response to gratings when targeted, when sharing one feature with the target or when irrelevant, independent of the spatial frequency of stimulation. (b) Mean amplitude values of P300 (330-600 ms), recorded in the same attention conditions as for the SN, no matter the spatial frequency considered.

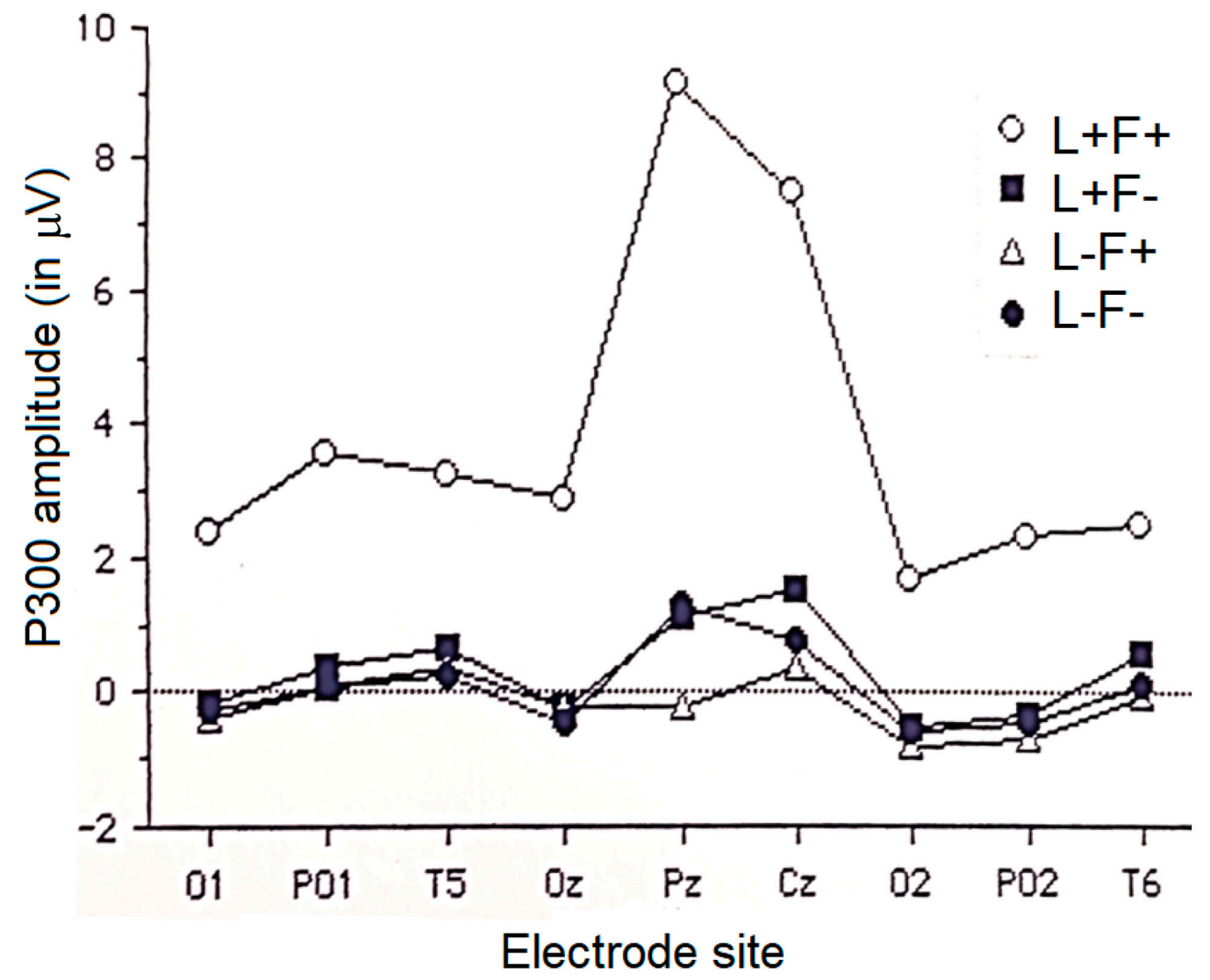

Figure 7. Mean area values recorded in response to spatial frequency gratings when targeted and when task-irrelevant at various central, parietal and posterior scalp sites, regardless of the spatial frequency of stimulation. A maximum distribution of this event-related potential (ERP) component at the midline centro-parietal scalp areas can be clearly observed. 


\section{Discussion}

The aim of this study was to explore the existence of hemispheric asymmetries for the attentional selection of spatial frequency gratings. Overall, the RTs to the target gratings presented in the RVF (left hemisphere) were faster than those of the stimuli presented in the LVF (right hemisphere), regardless of the grating's spatial frequency and the response hand. This would support the hypothesis, according to which the left hemisphere would have a greater selective capacity in subtle discrimination tasks [38], a more analytical attentional strategy [39] and would be dominant in object-based attentional selection [9].

Moreover, the ERP data showed that selective attention modulated the earliest sensory responses. $\mathrm{C} 1$ was larger in negativity in response to the targets $(\mathrm{L}+\mathrm{F}+)$ than to the frequency-specific stimuli $(\mathrm{L}+\mathrm{F}-)$. In turn, $\mathrm{C} 1$ elicited by the latter was more negative than that elicited by spatial frequency gratings irrelevant in both features. These results fit well with the more recent literature on ERP attentional modulation of the striate cortex during selective attention to grating spatial frequencies [37,40].

P1 was also modulated by attention, being more positive to targets than locationspecific stimuli. In turn, irrelevant stimuli elicited a smaller P1 than the gratings sharing only one feature with the target. As predicted by the literature, $\mathrm{C} 1$ was larger for the ipsilateral stimuli [41,42] and was enhanced in negativity by attention [43], while P1, focused on the lateral occipital sites and enhanced in positivity by attention [37,44], was larger than the contralateral stimuli.

The attentional effects grew as the post-stimulus processing latency increased and showed a more focused attentional gating for later latency components. Indeed, selection negativity, and even more for the P300 responses, were strongly enhanced by spatial frequency targeting and less responsive to the attentional relevance of one single feature (either location or the spatial frequency of the gratings). This evidence fits well with the previous ERP literature on spatial frequency selection [27,30-32,45], demonstrating that the bandwidth of selective attention effect narrowed during the course of the processing time.

In the present investigation, the most interesting piece of data was the hemispheric asymmetry in attentional selection, evidenced by the $\mathrm{C} 1$ and $\mathrm{P} 1$ sensory responses, also fitting with the behavioral data trend. Indeed, the C1 (60-100 ms) data showed that, for both the $6 \mathrm{c} /$ deg gratings $(p=0.0008)$ and the $1.5 \mathrm{c} / \mathrm{deg}$ gratings, the frequency-specific attentional effect $(\mathrm{L}+\mathrm{F}+\mathrm{vs}$. $\mathrm{L}+\mathrm{F}-)$ was stronger over the left hemisphere, irrespective of the visual field of stimulation. Consistently, at the P1 level (110-16 ms), the attentional effect was larger for stimuli presented in the RVF (left hemisphere), as shown by the significance of the triple interaction of attention $\times$ electrode $\times$ hemisphere.

This evidence of a left hemispheric advantage is consistent with previous ERP studies on object-based selective attention for shape [22], orientation [46], color [20], as well as local vs. global stimuli [4] and illusory contour detection [17]. When examined more closely, these data recall the left-sided attentional effect for the N1 response (100-200 ms) found in a task in which the orientation of the spatial frequency gratings was the target feature [47]. An N165 attentional modulation was also left-sided in a task requiring the selection of the check size of checkerboards of different spatial frequencies [29].

Overall, these data (which, to our knowledge, are the earliest latency effects of a hemispheric asymmetry in spatial frequency selection), fully support the theory advanced by Sergent [48], according to which the left hemisphere would be dominant in the processing of local elements of visual information, such as small check sizes, subtle bars or multiple luminance variations. Indeed, regardless of the response hand, we also found in the present study that targets were more quickly detected when they appeared in the observers' RVF (left hemisphere). From a broader perspective, this line of evidence might also account for the left hemispheric lateralization of the visual word form area (VWFA, namely the fusiform gyrus of the occipitotemporal cortex) devoted to orthographic processing [49,50], since letters are characterized by a high spatial frequency content. On the opposite side, the right hemispheric advantage for low spatial frequencies and global processing would explain 
the right-sided lateralization (at least in the male brain) of the fusiform face area (FFA) for the holistic recognition of faces $[16,51]$.

Author Contributions: Conceptualization, A.M.P.; methodology, A.M.P. and A.Z.; formal analysis and data curation, A.M.P.; writing — original draft preparation, A.M.P.; writing—review and editing, A.Z. All authors have read and agreed to the published version of the manuscript.

Funding: This research received no external funding.

Institutional Review Board Statement: The study was conducted according to the guidelines of the Declaration of Helsinki, and approved by the Ethics Committee of National Research Council (CNR).

Informed Consent Statement: Informed consent was obtained from all subjects involved in the study.

Data Availability Statement: The data that support the findings of this study are available from the corresponding author, upon reasonable request.

Acknowledgments: The authors are grateful to Alessandro Vegliach (AAS1, Univ. of Trieste) for his support in data collection.

Conflicts of Interest: The authors declare no conflict of interest.

Study Limits: One limit of the present investigation might be the limited sample size, so further investigation might be needed to corroborate the present findings that appear solid from the statistical point of view. Interestingly, the same experimental paradigm was carried out in the past [52], reporting a similar pattern of results and thus supporting its robustness and good test-retest reliability.

\section{References}

1. Christian, S. Cerebral Asymmetries in Sensory and Perceptual Processing, 1st ed.; Elsevier: Amsterdam, The Netherlands, 1997; ISBN 9780444825100.

2. Hellige, J.B.; Laeng, B.; Michimata, C. Processing asymmetries in the visual system. In The Two Halves of the Brain: Information Processing in the Cerebral Hemispheres; Hugdahl, K., Westerhausen, R., Eds.; MIT Press: Cambridge, MA, USA, 2010 ; pp. $379-415$.

3. Hugdahl, K. Hemispheric asymmetry: Contributions from brain imaging. Wiley Interdiscip. Rev. Cogn. Sci. 2011, 2, 461-478. [CrossRef] [PubMed]

4. Gable, P.A.; Poole, B.D.; Cook, M.S. Asymmetrical hemisphere activation enhances global-local processing. Brain Cognit. 2013, 83, 337-341. [CrossRef] [PubMed]

5. Van Kleeck, M.H. Hemispheric differences in global versus local processing of hierarchical visual stimuli by normal subjects: New data and a meta-analysis of previous studies. Neuropsychologia 1989, 27, 1165-1178. [CrossRef]

6. Yamaguchi, S.; Yamagata, S.; Kobayashi, S. Cerebral asymmetry of the "top-down" allocation of attention to global and local features. J. Neurosci. 2000, 20, RC72. [CrossRef]

7. Yovel, G.; Levy, J.; Yovel, I. Hemispheric asymmetries for global and local visual perception: Effects of stimulus and task factors. J. Exp. Psychol. Hum. Percept. Perform. 2001, 27, 1369-1385. [CrossRef] [PubMed]

8. Johannes, S.; Wieringa, B.M.; Matzke, M.; Münte, T.F. Hierarchical visual stimuli: Electrophysiological evidence for separate left hemispheric global and local processing mechanisms in humans. Neurosci. Lett. 1996, 210, 111-114. [CrossRef]

9. Proverbio, A.M. Left and Right Hemisphere Role for Selective and Sustained Attention: An Electrophysiological Approach. Ph.D. Thesis, University of Padua, Padua, Italy, 1993.

10. Proverbio, A.M.; Zani, A.; Avella, C. Hemispheric asymmetries for spatial frequency discrimination in a selective attention task. Brain Cognit. 1997, 34, 311-320. [CrossRef]

11. Robertson, L.C.; Lamb, M.R. Neuropsychological contributions to theories of part/whole organization. Cognit. Psychol. 1991, 23, 299-330. [CrossRef]

12. Robertson, L.C.; Lamb, M.R.; Knight, R.T. Effects of lesions of temporal-parietal junction on perceptual and attentional processing in humans. J. Neurosci. 1988, 8, 3757-3769. [CrossRef]

13. Navon, D. Forest before trees: The precedence of global features in visual perception. Cognit. Psychol. 1977, 9, 353-383. [CrossRef]

14. Christie, J.; Ginsberg, J.P.; Steedman, J.; Fridriksson, J.; Bonilha, L.; Rorden, C. Global versus local processing: Seeing the left side of the forest and the right side of the trees. Front. Hum. Neurosci. 2012, 22, 28. [CrossRef] [PubMed]

15. Proverbio, A.M.; Minniti, A.; Zani, A. Electrophysiological evidence of a perceptual precedence of global vs. local visual information. Cognit. Brain Res. 1998, 6, 321-334. [CrossRef]

16. Fink, G.R.; Halligan, P.W.; Marshall, J.C.; Frith, C.D.; Frackowiak, R.S.; Dolan, R.J. Where in the brain does visual attention select the forest and the trees? Nature 1996, 382, 626-628. [CrossRef] [PubMed]

17. Proverbio, A.M.; Zani, A. Electrophysiological indexes of illusory contours perception in humans. Neuropsychologia 2002, 40, 479-491. [CrossRef] 
18. Baas, J.M.; Kenemans, J.L.; Mangun, G.R. Selective attention to spatial frequency: An ERP and source localization analysis. Clin. Neurophysiol. 2002, 113, 1840-1854. [CrossRef]

19. Georgopoulos, A.P.; Whang, K.; Georgopoulos, M.A.; Tagaris, G.A.; Amirikian, B.; Richter, W.; Kim, S.; Uğurbil, K. Functional magnetic resonance imaging of visual object construction and shape discrimination: Relations among task, hemispheric lateralization, and gender. J. Cognit. Neurosci. 2001, 13, 72-89. [CrossRef]

20. Proverbio, A.M.; Burco, F.; Del Zotto, M.; Zani, A. Blue piglets? Electrophysiological evidence for the primacy of shape over color in object recognition. Cognit. Brain Res. 2004, 18, 288-300. [CrossRef]

21. Milham, M.P.; Banich, M.T.; Webb, A.; Barad, V.; Cohen, N.J.; Wszalek, T.; Kramer, A.F. The relative involvement of anterior cingulate and prefrontal cortex in attentional control depends on nature of conflict. Cognit. Brain Res. 2001, 12, 467-473. [CrossRef]

22. Orlandi, A.; Proverbio, A.M. Left-Hemispheric Asymmetry for Object-Based Attention: An ERP Study. Brain Sci. 2019, 9, 315. [CrossRef]

23. Corbetta, M.; Shulman, G.L. Spatial neglect and attention networks. Ann. Rev. Neurosci. 2011, 34, 569-599. [CrossRef]

24. Nobre, A.C.; Sebestyen, G.N.; Gitelman, D.R.; Mesulam, M.M.; Frackowiack, R.S.; Frith, C.D. Functional localization of the system for visuospatial attention using positron emission tomography. Brain 1997, 120, 515-533. [CrossRef] [PubMed]

25. Pardo, J.V.; Fox, P.T.; Raichle, M.E. Localization of a human system for sustained attention by positron emission tomography. Nature 1991, 349, 61-64. [CrossRef] [PubMed]

26. Proverbio, A.M.; Zani, A.; Avella, C. Differential activation of multiple current sources of foveal VEPs as a function of spatial frequency. Brain Topogr. 1996, 9, 59-68. [CrossRef]

27. Martınez, A.; Di Russo, F.; Anllo-Vento, L.; Hillyard, S.A. Electrophysiological analysis of cortical mechanisms of selective attention to high and low spatial frequencies. Clin. Neurophysiol. 2001, 112, 1980-1998. [CrossRef]

28. Dos Santos, N.A.; Andrade, S.M.; Fernandez Calvo, B. Detection of spatial frequency in brain-damaged patients: Influence of hemispheric asymmetries and hemineglect. Front. Hum. Neurosci. 2013, 7, 92. [CrossRef] [PubMed]

29. Zani, A.; Proverbio, A.M. ERP signs of early selective attention effects to check size. Electroencephalogr. Clin. Neurophysiol. 1995, 95, 277-292. [CrossRef]

30. Harter, M.R.; Previc, F.H. Size-specific information channels and selective attention: Visual evoked potentials and behavioural measures. Electroencephalogr. Clin. Neurophysiol. 1978, 45, 628-640. [CrossRef]

31. Harter, M.R.; White, C.T. Evoked cortical response to checkerboard patterns: Effect of check-size as a function of visual acuity. Electroencephalogr. Clin. Neurophysiol. 1970, 28, 48-54. [CrossRef]

32. Harter, M.R.; Aine, C.; Schroeder, C. Hemispheric differences in the neural processing of stimulus location and type: Effects of selective attention on visual evoked potentials. Neuropsychologia 1982, 20, 421-438. [CrossRef]

33. Mauguiere, F.; Giard, M.H.; Ibanez, V.; Pernier, J. Sequential spatial maps of visual potentials evoked by checkerboard-pattern reversal: Effect of the retinal field stimulated on response topography. Rev. Electroencephalogr. Neurophysiol. Clin. 1985, 15, 129-137. [CrossRef]

34. Hudnell, H.K.; Boyes, W.K.; Otto, D.A. Stationary pattern adaptation and the early components in human visual evoked potentials. Electroencephalogr. Clin. Neurophysiol. 1990, 77, 190-198. [CrossRef]

35. Blumhardt, L.D.; Barret, G.; Halliday, A.M.; Kriss, A. The effect of field size on the pattern reversal visual evoked response. Clin. Vis. Sci. 1989, 4, 27-40.

36. Bodis-Wollner, I.; Brannan, J.R.; Nicoll, J.; Frkovic, S.; Mylin, L.H. A short latency cortical component of the foveal VEP is revealed by hemifield stimulation. Electroencephalogr. Clin. Neurophysiol. 1992, 84, 201-208. [CrossRef]

37. Proverbio, A.M.; Del Zotto, M.; Zani, A. Electrical neuroimaging evidence that spatial frequency-based selective attention affects V1 activity as early as 40-60 ms in humans. BMC Neurosci. 2010, 11, 59. [CrossRef] [PubMed]

38. Reuter-Lorentz, P.A.; Kinsbourne, M.; Moscovitch, M. Hemispheric control of spatial attention. Brain Cognit. 1990, 12, 240-266. [CrossRef]

39. Palmer, T.; Tzeng, O.J. Cerebral asymmetry in visual attention. Brain Cognit. 1990, 13, 46-58. [CrossRef]

40. Papera, M.; Richards, A. Attentional gain and processing capacity limits predict the propensity to neglect unexpected visual stimuli. Psychophysiology 2016, 53, 634-649. [CrossRef]

41. Jeffreys, D.A.; Axford, J.G. Source locations of pattern-specific components of human visual evoked potentials. I. Component of striate cortical origin. Exp. Brain Res. 1972, 16, 1-21. [CrossRef]

42. Zani, A.; Proverbio, A.M. Selective attention to spatial frequency gratings affects visual processing as early as $60 \mathrm{msec}$. poststimulus. Percept. Mot. Skills 2009, 109, 140-158. [CrossRef]

43. Zani, A.; Proverbio, A.M. Is that a belt or a snake? Object attentional selection affects the early stages of visual sensory processing. Behav. Brain Funct. 2012, 8, 6. [CrossRef]

44. Zani, A.; Proverbio, A.M. Endogenous attention to object features modulates the ERP C1 component. Cogn. Neurosci. 2018, 9 , 66-67. [CrossRef]

45. Czigler, I.; Balázs, L.; Lénárt, A. Attention to features of separate objects: An ERP study of target-shooters and control participants. Int. J. Psychophysiol. 1998, 31, 77-87. [CrossRef]

46. Orlandi, A.; Proverbio, A.M. ERP indices of an orientation-dependent recognition of the human body schema. Neuropsychologia 2020, 146, 107535. [CrossRef] 
47. Proverbio, A.M.; Esposito, P.; Zani, A. Early involvement of the temporal area in attentional selection of grating orientation: An ERP study. Brain Res. Cogn. Brain Res. 2002, 13, 139-151. [CrossRef]

48. Sergent, J. The cerebral balance of power: Confrontation or cooperation? J. Exp. Psychol. Hum. Percept. Perform. 1982, 8, $253-272$. [CrossRef]

49. Proverbio, A.M.; Zani, A.; Adorni, R. The left fusiform area is affected by written frequency of words. Neuropsychologia 2008, 46 , 2292-2299. [CrossRef]

50. Fink, G.R.; Canário, N.; Jorge, L.; Castelo-Branco, M. Distinct mechanisms drive hemispheric lateralization of object recognition in the visual word form and fusiform face areas. Brain Lang. 2020, 210, 104860.

51. Hildesheim, F.E.; Debus, I.; Kessler, R.; Thome, I.; Zimmermann, K.M.; Steinsträter, O.; Sommer, J.; Kamp-Becker, I.; Stark, R.; Jansen, A. The Trajectory of Hemispheric Lateralization in the Core System of Face Processing: A Cross-Sectional Functional Magnetic Resonance Imaging Pilot Study. Front. Psychol. 2020, 11, 507199. [CrossRef]

52. Zani, A.; Proverbio, A.M. Attention modulation of short latency ERPs by selective attention to conjunction of spatial frequency and location. J. Psychophysiol. 1997, 11, 21-32. 